\title{
Tested Methods for Extracting Earthworms from Soil
}

\author{
Valentina SANDOR, Roxana VIDICAN*, Mignon SANDOR, Vlad STOIAN, Susana SFECHIS \\ ${ }^{1}$ University of Agricultural Sciences and Veterinary Medicine Cluj-Napoca, Mănăștur St., No. 3-5, \\ 400327 Cluj-Napoca, Romania; \\ * corresponding author: roxana.vidican@usamvcluj.ro
}

Bulletin USAMV series Agriculture 72(1)/2015

Print ISSN 1843-5246; Electronic ISSN 1843-5386

DOI 10.15835/buasvmcn-agr: 11121

\begin{abstract}
A comprehensive and quantitative knowledge of ecological factors affecting crop production is needed in purpose to meet the challenge of growing world population with minimal environmental impact. Earthworms are target organisms both for scientists studying the biological component of soils and for farmers concerned with monitoring the quality of their soils. For the growing social interest to quantify the role of earthworms in ecosystems, a precise and accurate estimation of their diversity, abundance and biomass is needed. Earthworm ecologists tend to use methods of extraction with less use of chemicals, with this purpose we want to test some new environmental friendly methods like chili powder, mustard powder, mustard-vinegar suspension, in comparison with formalin $0.1 \%$ ( $10 \mathrm{ml}$ in $8 \mathrm{l}$ water) and $0.2 \%$ (15 ml in $8 \mathrm{l}$ water). Efficiency of methods is compared in terms of earthworm species composition, numbers, biomass, ecological groups (epigeic, anecic, endogeic), development stages (adults + subadults vs. juveniles) and the mortality rates in the first week after sampling.
\end{abstract}

Keywords: chili, efficiency, formalin, mustard, vinegar.

\section{INTRODUCTION}

Soil biodiversity, especially earthworms have an essential role in soil functioning and ecosystem services.The role of engineers consist in fragmentation and incorporation of various organic materials, creation of tubular pores and assembly, stimulation of organisms and mixing organic with inorganic materials (Hoeffner et al., 2014). Because they are common and easy to observe (macroorganisms), they are recognized as status indicator and land use (Oberholzer et al., 2012). The common interest of all these people is to move toward sustainable agriculture, producing enough yields while limiting environmental damage. In order to assess human impacts on soil biodiversity and soil invertebrate biomass, earthworms have been sampled by scientists for several decades (Evans and Guild, 1948) and more and more by the general public using standardized and simplified protocols (Pelosi et al., 2014).
Up to the present a diverse set of earthworm sampling methods is available, and a diverse amount of chemical expellants have been used to greater or lesser success (Bartlett et al., 2010; Lawrence and Bowers, 2002; Zaborski, 2003; Coja et al., 2008; Pelosi et al., 2009, 2014; Valckx et al., 2011).

\section{MATERIAL AND METHODS}

First, five protocols have been established, oneforeachsubstance(Tab.1).Previouspreparation have been made in case of the suspension consisting of mustard-vinegar, therefore we mixed one liter of vinegar with 80 grams of mustard powder and we stirred them together, then we left it 24 hours for homogenization. All the substances were prepared 1 hour before application by adding the appropriate amount of powder to $8 \mathrm{l}$ of water and stirring heavily, in case of chili powder we used hot water for a better homogenization. 
Tab. 1. Concentrations per application in the efficiency assessment

\begin{tabular}{cccccc}
\hline ID & Expellant & Unit & $\begin{array}{c}\text { Quantity } \\
\text { (in 8 l water) }\end{array}$ & $\begin{array}{c}\text { \% of expellant } \\
\text { in water }\end{array}$ & Status \\
\hline $\mathrm{C}$ & Chili & $\mathrm{g} \mathrm{l}^{-1}$ & $30 \mathrm{~g}$ & 0.38 & Environmental friendly \\
$\mathrm{M}$ & Mustard & $\mathrm{g} \mathrm{l}^{-1}$ & $80 \mathrm{~g}$ & 1.00 & Environmental friendly \\
$\mathrm{MV}$ & Mustard-Vinegar & $\mathrm{g} \mathrm{l} \mathrm{l}^{-1}$ & $80 \mathrm{~g}+1 \mathrm{l}$ & 1.00 & Environmental friendly \\
$\mathrm{F}_{1}$ & Formalin & $\mathrm{ml} \mathrm{l}^{-1}$ & $10 \mathrm{ml}$ & 0.1 & Chemical \\
$\mathrm{F}_{2}$ & Formalin & $\mathrm{ml} \mathrm{l}^{-1}$ & $15 \mathrm{ml}$ & 0.2 & Chemical \\
\hline
\end{tabular}

Formalin solutions were prepared by diluting the appropriate volume of formalin $(10 \mathrm{ml}$ and $15 \mathrm{ml})$ in $8 \mathrm{l}$ water.

Expellant concentrations were tested in November 2014 in USAMV Cluj-Napoca yard. Earthworms were sampled by each expellant concentration in three replicate plots $\left(\mathrm{S}=1.77 \mathrm{~m}^{2}\right)$. Expellants were sprinkled with a watering can over the plot area. Two successive applications of $4 \mathrm{l}$ each with a period of $15 \mathrm{~min}$ between applications to collect emerging earthworms were used.

Earthworms were collected starting with the first minutes of the expellant application for up to 30 minutes. The weather condition before sampling was without precipitations for about 2 weeks. And the temperatures vary between $\min 0{ }^{\circ} \mathrm{C}$ and $\max$ $22 \stackrel{\circ}{\circ}$. Statistical analysis of experimental data was done with statistical software (StatSoft, 2012).

\section{RESULTS AND DISCUSSION}

All the earthworms were determined after extracting them from the soil and we discovered only two different species named Aporrectodea caliginosa (A.c) and Lumbricus terrestris (L.t) (Fig 1). The most abundant species was Lumbricus terrestris (Fig. 2, 3) and the most sensitive species was Aporrectodea caliginosa which has as well high mortality rates. In general, we observed that we extracted more earthworm individuals with formalin rather than with the other environmental friendly substances, but also with a high mortality rates (Fig. 4), results obtained in similar extractions by other authors (Valckx et al., 2011). Interestingly, despite of the difference in abundance, the average number of individuals (13) extracted with the two concentrations of formalin, the biomass was much higher in the extraction with $0.1 \%$ formalin rather than $0.2 \%$ formalin, $23.23 \pm 1.33 \mathrm{~g}$ and $10.10 \pm 1.06$ g respectively (Fig. 5, 6). A high total biomass of
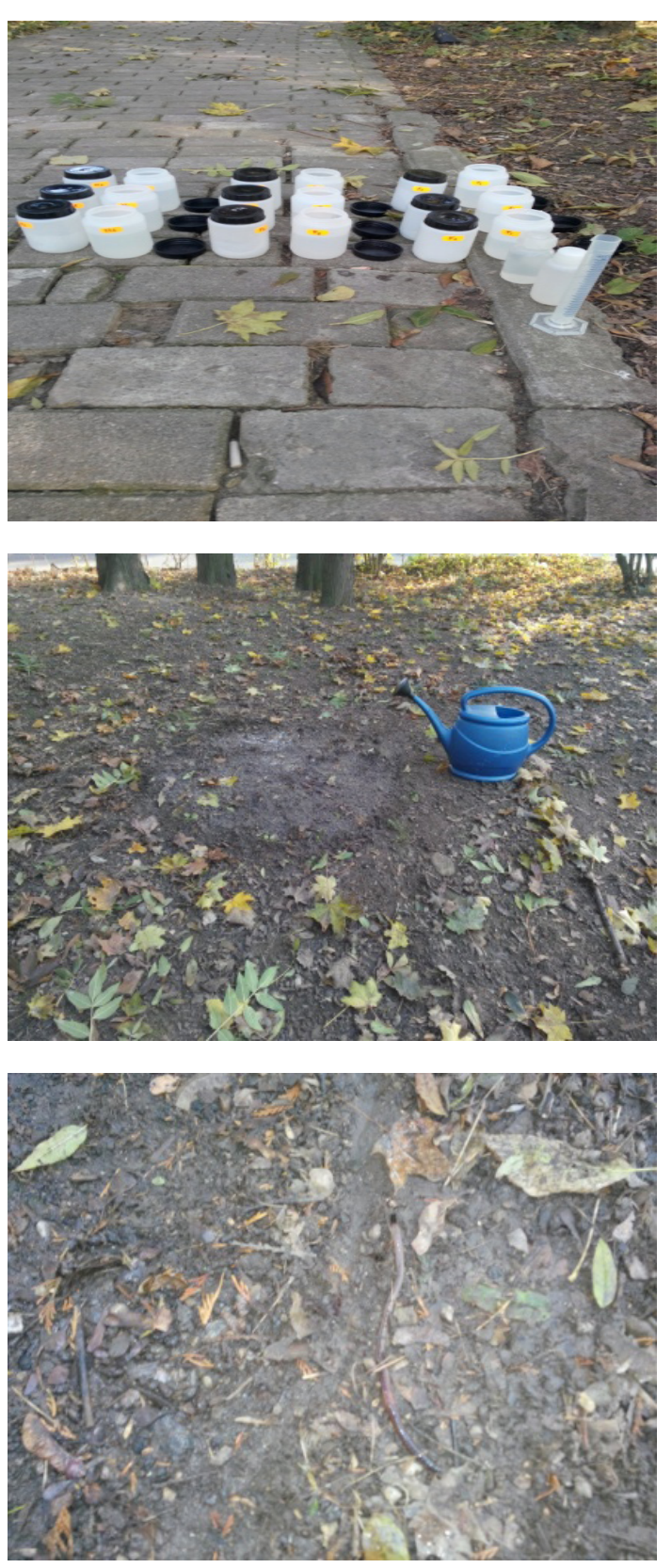

Fig. 1. Earthworms extraction procedure 


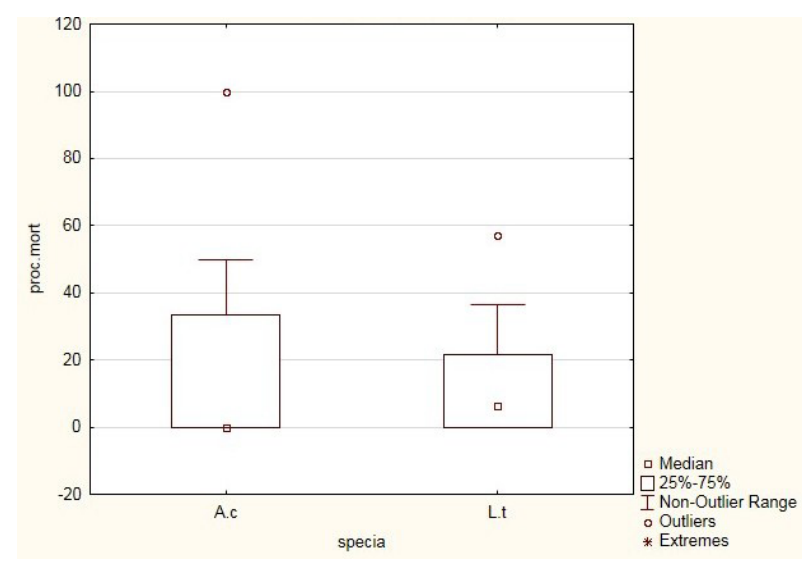

Fig. 2. Mortality percent between the extracted species Aporrectodea caliginosa (A.c) and Lumbricus terrestris (L.t)

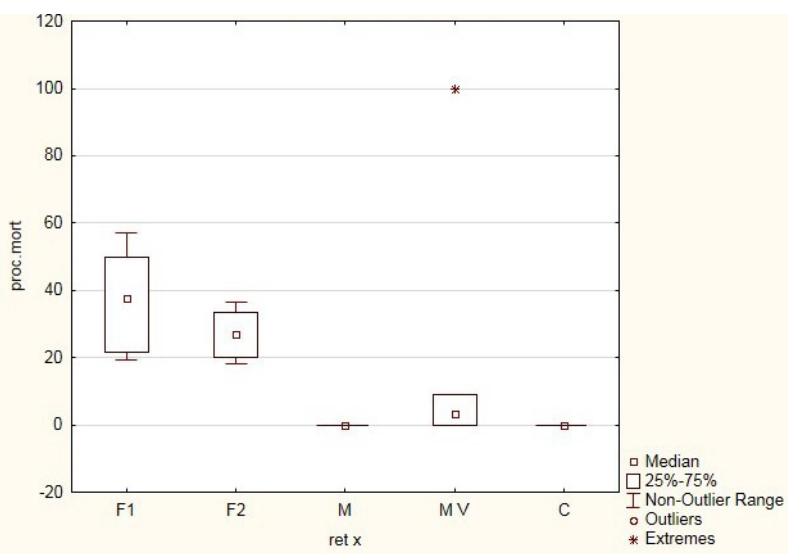

Fig. 4. The influence of the expellant on the mortality of earthworms (F1,2-formalin, M-mustard, MV-mustard and vinegar, C-chili)
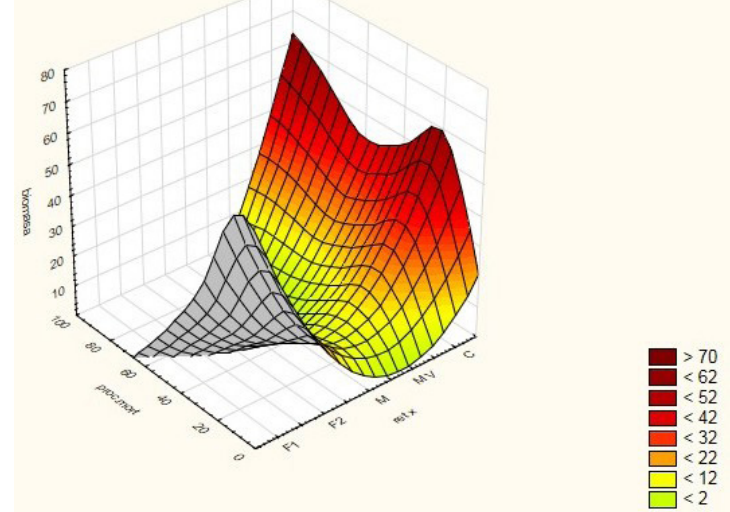

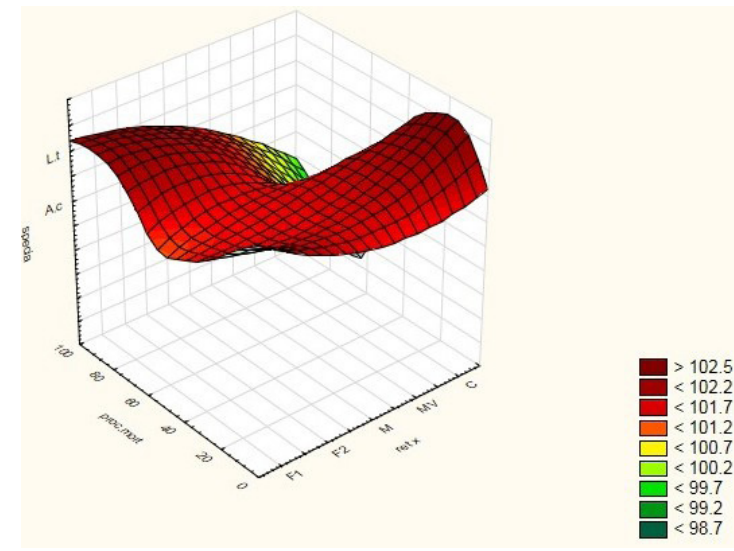

Fig. 3. Plot 3D between extracted species, expelland and percent of mortality

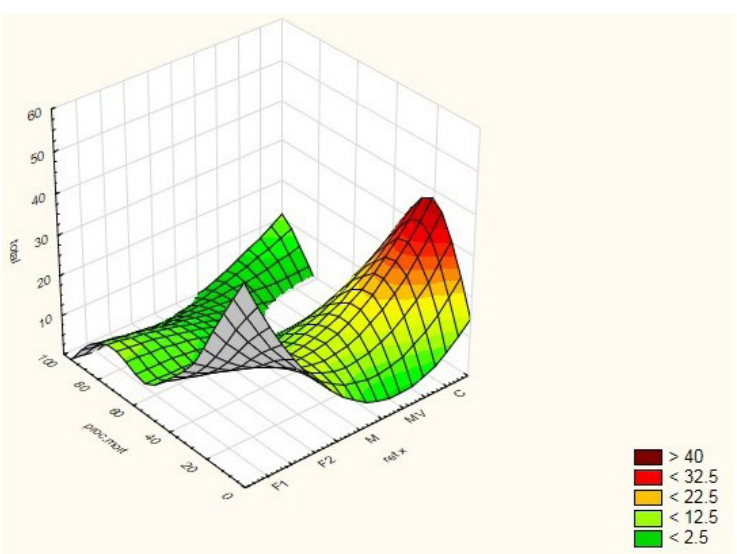

Fig. 5. Plot 3D between total number of individuals extracted with each expellant and the percent of the mortality

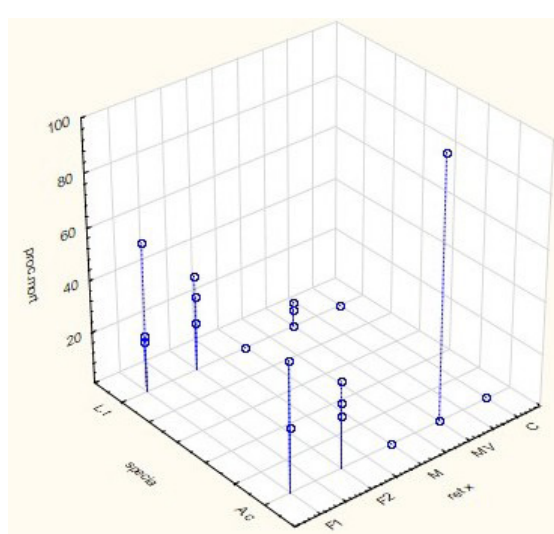

Fig. 6. Plot 3D between total biomass of individuals extracted with expellants and mortality percent 
earthworms was observed in the extraction with chili $(15.78 \pm 1.33 \mathrm{~g})$ compared to low values in case of mustard repellent $(5.39 \pm 0.77 \mathrm{~g})$ and mustardvinegar $(8.39 \pm 0.97 \mathrm{~g})$, in the last two cases we had also the lowest number of individuals per extraction. If we take singular species biomass, in case of Aporrectodea caliginosa we obtained lower biomass in case of the extraction with mustard $(0.33 \pm 0.17 \mathrm{~g})$ and chili $(2 \pm 0.42 \mathrm{~g})$ and high biomass when both concentrations of formalin were used in a range of 5.06-5.20 g. The mustard extraction didn't have the same impact to earthworms reported recently by (Pelosi et al., 2014; Valckx et al., 2011). Common earthworm biomasses were higher in extraction with formalin $0.1 \%(33.73 \pm 1.72 \mathrm{~g})$ and chili $(18 \pm 1.5 \mathrm{~g})$.

The present results clearly indicated the advantages and efficiencies of environmental friendly vermifuge in comparison with the chemical agent - formalin (Pelosi et al., 2014). Our results demonstrated that the juveniles of Aporrectodea caliginosa and Lumbricus terrestris were more sensitive to chili concentration. Mustard was also very good at bringing to the surface subterranean slugs as was observed also by Gunn in 1992.

\section{CONCLUSION}

This study highlights that chili could be an environmental friendly alternative for sampling mainly Aporrectodea caliginosa juveniles. Mustard and vinegar was effective for sampling endogeic species like Aporrectodea caliginosa but not for an endogeic species Lumbricus terrestis. Chili, mustard and vinegar repellents have many advantages in comparison with phytotoxic effect of formalin that include cheapness, ready availability, and simplicity of application as well a very rapid effect of extraction.

Acknowledgements: This paper was published under the frame of European Social Fund, Human Resources Development Operational Program 2007-2013, project no. POSDRU/159/1.5/ S/132765.

\section{REFERENCES:}

1. Bartlett MD, Briones MJI, Neilson R, Schmidt O, Spurgeon D, Creamer RE (2010). A critical review of current methods in earthworm ecology: from individuals to populations. Eur. J. Soil Biol. 46:67-73.

2. Coja T, Zehetner K., Bruckner A, Watzinger A, Meyer E (2008). Efficacy and side effects of five sampling methods for soil earthworms (Annelida Lumbricidae). Ecotoxicol. Environ. Saf. 71:552-565.

3. Evans AC, Guild McL WJ (1948). Studies on the relationships between earthworms and soil fertility. Ann. Appl. Biol. 35:485-493.

4. Gunn A (1992), The use of mustard to estimate earthworm population, Pedobiologia 36, 65-67.

5. Hoeffner K., Hotte HM, Guernion N, Delaveau N, Poupelin M, Peres G, Piron D, Cluzeau D (2014). The participative earthworm observatory- a citizen science project at a national scale, Dijon Conference.

6. Lawrence AP, Bowers MA (2002). A test of the hot mustard extraction method of sampling earthworms. Soil Biol. Biochem. 34:549-552.

7. Oberholzer HR, Knuchel RF, Weisskopf P, Gaillard G (2012). A novel method for soil quality in life cycle assessment using several soil indicators. Agron. Sustain. Dev. 32:639-649.

8. Pelosi C, Bertrand M, Capowiez Y, Boizard H, RogerEstrade J (2009). Earthworm collection from agricultural fields: comparisons of selected expellants in presence/ absence of hand-sorting. Eur. J. Soil Biol. 45:176-183.

9. Pelosi C, Chiron F, Dubs F, Hedde M, Ponge JF, Salmon S, Cluzeau D, Nélieu S (2014). A new method to measure allyl isothiocyanate (AITC) concentrations in mustardComparison of AITC and commercial mustard solutions as earthworm extractants, Applied Soil Ecology 80:1-5.

10. Valckx J, Govers G, Hermy M, Muys B (2011). Optimizing earthworm sampling in ecosystems. Biology of Earthworms. Springer, Berlin, 19-38.

11. Van Groenigen JW, Lubbers IM, Vos HMJ, Brown GG, De Deyn GB, van Groenigen KJ (2014). Earthworms increase plant production: a meta-analysis, Scientific report, Ecosystem services agroecology, DOI:10.1038/ srep06365:1-7.

12. Zaborski ER (2003). Allyl isothiocyanate: an alternative chemical expellant for sampling earthworms. Appl. Soil Ecol. 22:87-95. 